\title{
A systematic approach to the unconscious patient
}

\author{
Authors: Tim Cooksley, ${ }^{A}$ Sarah Rose ${ }^{B}$ and Mark Holland ${ }^{C}$
}

\begin{abstract}
Unconscious patients are commonly seen by physicians. They are challenging to manage and in a time sensitive condition, a systematic, team approach is required. Early physiological stability and diagnosis are necessary to optimise outcome. This article focuses on unconscious patients where the initial cause appears to be non-traumatic and provides a practical guide for their immediate care.
\end{abstract}

\section{Introduction}

Although unconscious patients most commonly present to the Emergency Department, the competencies to care for these patients are required by acute and general physicians. ${ }^{1,2}$ Unless the cause of unconsciousness is immediately obvious and reversible, both early senior physician and critical care input are required, especially when the prognosis is poor and decisions regarding ceiling of care or cardiopulmonary resuscitation are needed.

\section{Definition and pathophysiology}

Patients present with a spectrum of altered consciousness. Impaired consciousness can be considered in terms of reduced alertness/ability to be aroused, awareness or both, with coma defined as 'a completely unaware patient unresponsive to external stimuli with only eye opening to pain with no eye tracking or fixation, and limb withdrawal to a noxious stimulus at best (often with reflex motor movements). ${ }^{3}$ When describing consciousness imprecise terms such as 'drowsy' or 'mildly unconscious' should be avoided in favour of a clear description of the patient's actual condition and functional abilities. ${ }^{3}$

There are two main mechanisms to explain coma. The first is a diffuse insult to both cerebral hemispheres and the second a disruption of the ascending reticular activating system in the midbrain and pons, where signals are carried to the thalamus and cortex. The thalamus plays a crucial role in maintaining arousal. The thalamus and ascending reticular activating system can be damaged either by direct insult or by problems arising within the brainstem. $^{3,4}$


South Manchester, UK; ${ }^{B}$ consultant in acute medicine, Salford Royal NHS Foundation Trust, UK; ${ }^{C}$ consultant in acute medicine, Salford Royal NHS Foundation Trust

\section{Differential diagnoses}

There are four main categories (see Table 1):

$>$ neurological

$>$ metabolic

> diffuse physiological brain dysfunction eg drugs or alcohol

> psychiatric or functional - considered when organic causes have been excluded.

\section{Clinical approach}

General principles of initial assessment and management

The four core components of care, history, examination, investigation and treatment/management should occur in parallel. ${ }^{3-6}$ A systematic and structured ABCDE (airway, breathing, circulation, disability, exposure) approach should be employed by teams caring for unconscious patients (Fig 1). Supportive care and specific treatments must not be delayed.

\section{Key points}

Unconsciousness is a time-sensitive medical emergency where early physiological stability and diagnosis are vital in optimising patient outcomes

An initial assessment of airway, breathing, and circulation must be performed to identify and manage the most immediate threats to life

All facets of care, history, examination, investigation and treatment/management should be delivered in parallel by a team working in a systematic way

Even in the apparent absence of trauma, especially in older patients or patients taking anticoagulants, brain injury or trauma should still be considered

Senior physicians must be involved early in the care of an unconscious patient, to liaise with critical care and speak with the patient's relatives or advocates, especially when decisions regarding cardiopulmonary resuscitation or ceiling of care are required

KEYWORDS: unconscious, coma, neurological injury, hypoglycaemia, drug toxicity 
Table 1. Differential diagnoses in a patient with non-traumatic coma

$\begin{array}{llll}\text { Neurological } & \text { Metabolic } & \text { Diffuse physiological brain dysfunction } & \text { Psychiatric } \\ \text { Ischaemic stroke } & \text { Hypoglycaemia } & \begin{array}{l}\text { Seizures - including nonconvulsive } \\ \text { status epilepticus }\end{array} & \begin{array}{l}\text { Psychiatric } \\ \text { coma }\end{array} \\ \text { Intracerebral haemorrhage } & \text { Hyperglycaemia } & \text { Alcohol intoxication } & \text { Malingering } \\ \text { Subarachnoid haemorrhage } & \text { Hyponatraemia } & \text { Opioid toxicity } & \text { Drug overdose } \\ \text { Subdural haematoma } & \text { Hypernatraemia } & \text { Poisoning } \\ \text { Brain tumour } & \text { Hypercalcaemia } & \text { Hypothermia } \\ \text { Cerebral lymphoma } & \text { Addisonian crisis } & \text { Neuroleptic malignant syndrome } \\ \text { Multiple brain metastases } & \text { Hypothyroidism } & \text { Serotonin syndrome } \\ \text { Central nervous system infection } & \text { Uraemia } & \\ \text { Cerebral abscess } & \text { Hypercapnia } & \\ \text { Cerebral oedema } & \text { Septic encephalopathy } & \\ \text { Hydrocephalus } & \text { Hepatic encephalopathy } & \\ \text { Anoxic brain injury (eg post cardiac arrest) } & & \\ \text { Posterior reversible encephalopathy syndrome (PRES) } & & \\ \text { Trauma } & \end{array}$

\section{History}

A collateral history from relatives or other witnesses, including paramedics, is vital. ${ }^{4}$ The patient's recent health, functional status and previous medical history may provide diagnostic clues as well as guiding decisions regarding ongoing care, such as admission to a critical care unit. Previous hospital records must be requested urgently and the next of kin contacted. Hospital pharmacists can obtain a drug history from primary-care shared records. Bystanders may have witnessed the patient collapse, while paramedics are skilled in surveying the scene for clues, such as empty drug packets, alcohol or a suicide note.

\section{Examination}

After the initial $A B C$ assessment, the level of consciousness should be formally measured and documented using the Glasgow Coma Scale (GCS) (see Table 2). Coma is defined as having a GCS $<8$ or scoring $U$ on the AVPU (Alert, responsive to Voice, responsive to Pain, Unresponsive) scale. ${ }^{7}$ A focused neurological examination should be undertaken. Motor responses can be purposeful, such as the patient pulling on

\section{Table 2. The Glasgow Coma Scale}

$\begin{array}{lll}\text { Eye opening } & \text { Movement } & \text { Verbal } \\ \text { 4-Spontaneous } & 6 \text { - Obeys commands } & 5 \text { - Oriented } \\ \text { 3-To speech } & 5 \text { - Localises to pain } & \text { 4-Confused } \\ \text { 2-To pain } & \text { 4- Withdraws from } & \text { 3- Inappropriate } \\ & \text { pain } & \text { words } \\ \text { 1-None } & \text { 3- Abnormal } & \text { 2-Incomprehensible } \\ & \text { flexion to pain } & \text { sounds } \\ & \text { 2- Extensor response } & \text { 1- None } \\ & \text { to pain } & \\ & \text { 1- No response } & \end{array}$

an airway adjunct, or reflexive, including withdraw, flexion or extension responses. ${ }^{3}$ Motor response to graded stimuli should be assessed in a stepwise approach: ${ }^{8}$

> verbal stimulus - eg 'Can you hear me?'

$>$ tactile stimulus - to hands or face

> noxious stimulus - intense but not causing injury, eg pressure on nailbed or supraorbital ridge.

Eye movements cannot be fully assessed in an unconscious patient. If there is no concern regarding a neck injury, the doll's eyes or oculocephalic reflex can be performed. A loss of conjugate eye movement away from the direction the head is moved, with the eyes remaining in a midorbit position, suggests brain stem dysfunction. Fundoscopy should be performed; important findings include papilloedema in posterior reversible encephalopathy syndrome (PRES) or subhyaloid haemorrhage in subarachnoid haemorrhage. Pupil examination can aid diagnosis: ${ }^{3-5}$

$>$ small pupils $(<2 \mathrm{~mm})$ - opioid toxicity or a pontine lesion

$>$ midsize pupils $(4-6 \mathrm{~mm}$ ) unresponsive to light - midbrain lesion

$>$ maximally dilated pupils (>8 $\mathrm{mm})$ - drug toxicity, eg anticholinergic overdose

> mixed and dilated pupil(s) - 3rd (oculomotor) nerve lesion from uncal herniation.

A full examination must be performed, although there are areas of specific relevance in the unconscious patient. The breath may exhibit the musty smell of hepatic encephalopathy or the garlic smell of organophosphate poisoning. ${ }^{9,10}$ When the breath suggests alcohol consumption, a thorough search for other causes of unconsciousness should continue. In older people, especially those taking anticoagulant medication, an intracranial bleed remains a strong possibility, even in the absence of a history of falls or external injury. However, older people often have evidence of minor injuries, such as bruises, which should alert the attending physician to more serious intracranial pathology. The presence of generalised tremor or myoclonus 
Fig 1. Systematic team approach to the unconscious patient. $A B C D E$ = airway, breathing, circulation, disability, exposure; $\mathrm{CT}$ = computed tomography; $\mathrm{CXR}=$ chest $\mathrm{X}$-ray

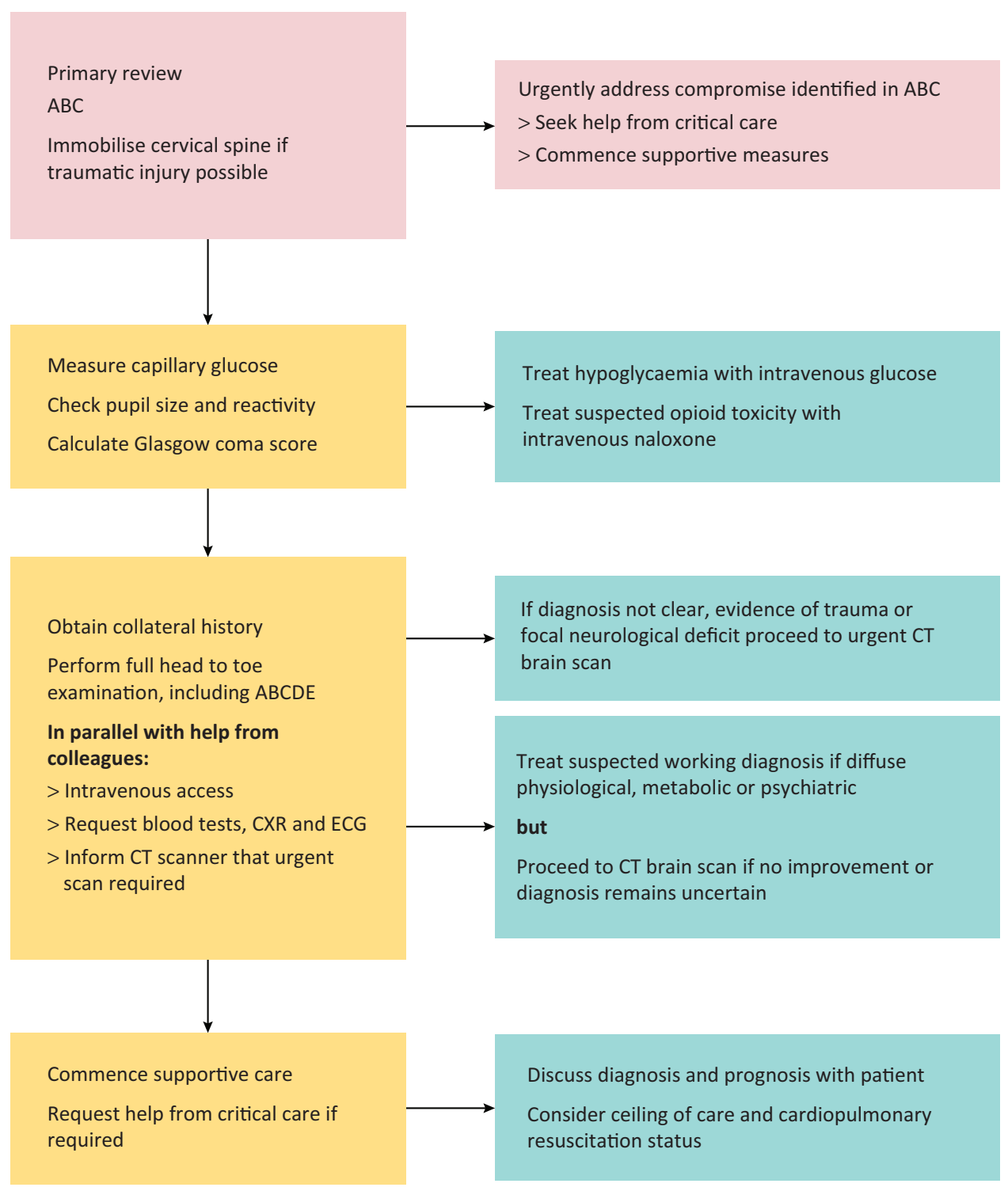

points towards a metabolic cause. Examination of the skin may reveal drug injection sites.

The pattern of breathing should be assessed as well as the respiratory rate.

> Kussmaul respiration - deep, laboured breathing, indicative of severe metabolic acidosis and commonly associated with diabetic ketoacidosis.

> Shallow with an extremely depressed respiratory rate seen in opiate overdose.

> Ataxic breathing (Biot's respiration) - groups of quick, shallow inspirations followed by regular or irregular periods of apnoea, suggesting a lesion in the lower pons. ${ }^{11}$

> Central neurogenic hyperventilation - breathing characterised by deep and rapid breaths at a rate of at least 25 breaths per minute indicating a lesion in the pons or midbrain. ${ }^{12}$

$>$ Cheyne-Stokes breathing is seen with many underlying pathologies and is not helpful in making a firm diagnosis.

\section{Investigations}

Investigations aid diagnosis, assessment of severity and monitoring of ongoing care. Before considering any further investigations, a bedside capillary blood glucose must be performed to exclude hypoglycaemia (Box 1).

Urgent imaging of the brain is important and a structural pathology should always be considered if the cause of unconsciousness is not obvious from the initial rapid assessment. ${ }^{3-6}$ Computed tomography (CT) of the brain is the investigation of choice to exclude common pathologies such as intracranial blood, stroke or space-occupying lesions. If the $\mathrm{CT}$ brain scan is normal and the diagnosis remains unclear, further imaging with a magnetic resonance scan may be required.

If there is no contraindication, a lumbar puncture should be considered when the cause of unconsciousness remains unclear or a central nervous system infection is suspected. 
Box 1. Initial investigations in an unconscious patient

$>$ Full blood count

$>$ Blood glucose - even if the capillary blood glucose is normal

$>$ Urea and electrolytes

$>$ Calcium and bone profile

$>$ Liver function tests

$>$ Clotting screen

> Toxicology screen - including paracetamol, salicylate and blood alcohol level electrocardiogram (ECG)

$>$ Chest X-ray

$>$ Arterial blood gas - including carbon monoxide concentration

$>$ Blood cultures should be taken from patients with fever or suspected sepsis, preferably before the administration of empirical antibiotics

Other microbiology samples should be taken based on the clinical assessment

Electroencephalography (EEG) should be performed in suspected cases of non-convulsive status epilepticus. In this condition there is prolonged seizure activity but in the absence of motor signs. It is more common in older patients. Clinically, patients appear to stare into space with nystagmus-like eye movements, lip smacking or myoclonic jerks. ${ }^{13}$

\section{Treatment and management}

As the $A B C$ assessment is undertaken, other team members should be:

$>$ taking blood tests

$>$ establishing intravenous access

$>$ connecting the patient to a cardiac monitor and oxygen saturation probe

> commencing appropriate oxygen therapy if indicated.

If any doubt exists, the cervical spine should be immobilised. Death will occur soonest when the airway and breathing are compromised; therefore, intubation should be considered in patients with a GCS of 8 or less, or those who cannot protect their own airway or have ineffective respiratory drive and poor oxygenation. Hypotension is initially manged with intravenous fluid resuscitation; early vasopressor support is considered when the blood pressure does not respond. In patients who remain physiologically unstable or where the cause of coma is not immediately clear or reversible, help from critical care colleagues must be sought at a very early stage. ${ }^{4,5,14}$

If raised intracranial pressure is suspected the patient should be managed in a $30^{\circ}$ head tilt position. Unconscious patients with an acute neurological condition should be discussed with either a neurosurgeon, neurologist or stroke physician to determine further management. ${ }^{4,14}$ Concussion results in neurological signs and symptoms following a force injury to the brain, which may be minor, with the absence of macroscopic neural damage. ${ }^{15}$

Specific treatment depends on the underlying aetiology of the coma. 'Coma cocktails' should be avoided. ${ }^{3}$ In cases where there is clinical suspicion of toxicity, specific antidotes should be used, eg naloxone in opiate toxicity. In hypoglycaemia, intravenous glucose is the immediate treatment of choice as glucagon can take up to 15 minutes to act and is ineffective in patients with liver disease, depleted glycogen stores or malnutrition. In hypoglycaemic patients at risk of Wernicke's encephalopathy, such as those with a history of alcohol excess, intravenous thiamine should be coadministered. Although flumazenil can be considered in benzodiazepine overdose, it is contraindicated in patients with a history of seizures and can provoke seizures with concomitant tricyclic overdose.

\section{Prognosis}

Prognosis depends on a number of factors. In one systematic review the mortality rate varied from $25-87 \% .{ }^{14}$ Non-traumatic unconscious patients presenting with a stroke have the highest mortality, while those presenting with epilepsy and poisoning have the best prognosis. ${ }^{14,16,17}$ A Swedish study of coma patients presenting to the Emergency Department found initial inpatient mortality to be $27 \%$, rising to $39 \%$ at 1 year. ${ }^{18}$ Patients with a lower GCS at presentation, 3-5, have a significantly higher mortality than those with a GCS of 7-10. ${ }^{19}$

Reversible causes of coma are generally more likely when a CT scan of the brain is unremarkable and the patient has no focal neurology. Patients not responding to initial treatment and who remain comatose are likely to require critical care admission unless withdrawal of treatment and palliation of symptoms is more appropriate. Early communication with the next of kin, family or appropriate advocate is always necessary. When the prognosis is poor these discussions will include ceiling of care, consideration of future withdrawal of treatment and cardiopulmonary resuscitation.

\section{Training in the care of unconscious patients}

The challenges of managing unconscious patients lend themselves to standardised multidisciplinary approaches and algorithms. A 'coma alarm', an alarm-triggered management routine designed for patients presenting with coma, has been shown to optimise assessment and treatment. ${ }^{6}$ Checklists for healthcare professionals have also shown utility in the management of coma. ${ }^{20}$ Intuitively, simulation-based education is an ideal way to train a multidisciplinary team to work collaboratively and effectively. Simulation training for core medical trainees in the care of unconscious patients has shown some positive effect. ${ }^{21}$

\section{Conclusion}

The unconscious patient is challenging, in terms of immediate care, diagnosis, specific treatment and predicting prognosis. A systematic and logical approach is required, with an emphasis on teamwork. Appropriate measures to resuscitate, stabilise and support an unconscious patient must be performed rapidly. Unless the cause of coma is immediately obvious and reversible, input from senior physicians and critical care colleagues is necessary. Decisions, such as ceiling of care, are required at an early stage in patients with a poor prognosis.

\section{References}

1 Joint Royal Colleges of Physicians Training Board. Specialty training curriculum for Acute Internal Medicine. London: JRCPTB, 2009. (amendments August 2012). 
2 Joint Royal Colleges of Physicians Training Board. Specialty training curriculum for General Internal Medicine. London: JRCPTB, 2009. (amendments August 2012).

3 Wijdicks E. The bare essentials. Pract Neurol 2010;10:51-60.

4 Edlow J, Rabinstein A, Traub S, Wijdicks E. Diagnosis of reversible causes of coma. Lancet 2014:384:206476.

5 Cooksley T, Holland M. The management of coma. Medicine 2017:45:115-19.

6 Braun M, Schmidt WU, Mockel M, Romer M et al. Coma of unknown origin in the emergency department: implementation of an in-house management routine. Scand J Trauma Resusc Emerg Med 2016;24:61.

7 Kelly C, Upex A, Bateman D. Comparison of consciousness level assessment in the poisoned patient using the alert/verbal/painful/ unresponsive scale and the Glasgow Coma Scale. Ann Emerg Med 2004:44:108-13.

8 Huff JS, Stevens R, Weingart S, Smith WS. Emergency neurological life support: approach to the patient with coma. Neurocrit Care 2012;17:S54-9.

9 Gowda B, Sundharam, Mahadesh J, Mukund. Oral-toxicology. J Forensic Dent Sci 2014;6:3-8.

10 Kamanyire R, Karalliedde L. Organophosphate toxicity and occupational exposure. Occup Med 2004;54:6975.

11 Wijdicks E. Biot's breathing. J Neurol Neurosurg Psychiat 2007;78:512-3.

12 Esquivel G, Schruers KR, Maddock R, Colasanti A, Griez E. Acids in the brain: a factor in panic? J Psychopharmacol 2010;24:639-47.

13 Zubler F, Koenig C, Steimer A et al. Prognostic and diagnostic value of EEG signal coupling measures in coma. Clinical Neurophysiol 2016; 127;2942-52.

14 Horsting M, Franken M, Meulenbelt ], van Klei W, de Lange D. The etiology and outcome of non-traumatic coma in critical care: a systematic review. BMC Anesthesiol 2015;15:65.
15 Giza C, Hovda D. The new neurometabolic cascade of concussion. Neurosurgery 2014;75:S24-33.

16 Forsberg S, Hojer J, Ludwigs U, Nystrom H. Metabolic vs structural coma in the ED - An observational study. Am J Emerg Med 2012;30:1986-90.

17 Weiss N, Regard L, Vidal C, Luque Y et al. Causes of coma and their evolution in the medical intensive care unit. J Neurol 2012; 259:1474-7.

18 Forsberg S, Hojer J, Ludwigs U. Prognosis of patients presenting with nontraumatic coma. J Emerg Med 2012; 42:249-53.

19 Sacco R, Van Gool R, Mohr JP, Hauser WA. Nontraumatic coma. Glasgow Coma Score and coma etiology as predictors of 2 week outcome. Arch Neurol 1990; 47:1181-4.

20 Subbe CP, Kellett J, Barach P et al. Crisis Checklist Collaborative. Crisis checklists for in-hospital emergencies: expert consensus, simulation testing and recommendations for a template determined by a multi-institutional and multi-disciplinary learning collaborative. BMC Health Serv Res 2017;17:334.

21 Joint Royal Colleges of Physicians Training Board / Health Education England Expert Group on Simulation in Core Medical Training. Enhancing UK Core Medical Training through simulation based education: an evidence-based approach. London: JRCPTB and Leeds: HEE, 2016.

Address for correspondence: Dr Tim Cooksley, University Hospital of South Manchester, Southmoor Road, Wythenshawe, Manchester M23 9LT, UK.

Email: cooks199@hotmail.com 